\title{
Avaliação energética da produção de etanol utilizando como matéria-prima a cana-de-açúcar
}

\author{
Energy evaluation of the etanol production using as raw-material the sugar cane
}

\author{
Diones Assis Salla ${ }^{\mathrm{I}}$ Fernanda de Paiva Badiz Furlaneto ${ }^{\mathrm{II} *}$ Claudio Cabello $^{\mathrm{III}}$ \\ Ricardo Augusto Dias Kanthack ${ }^{\text {II }}$
}

\section{RESUMO}

Analisou-se energeticamente a produção de etanol originária da cana-de-açúcar. As pesquisas de campo foram realizadas na região paulista do Médio Paranapanema, no período de janeiro a dezembro de 2007, avaliando-se o consumo energético referente às fases de produção $e$ processamento industrial. Verificou-se que o custo energético total da produção agrícola correspondeu a 14.370,9MJ ha ${ }^{-1}$, e o item mais oneroso foi o de "insumos" (50,4\%). Nas etapas industriais, o consumo energético foi equivalente a 1.641,6MJ $t^{-1}$. As operações de "hidrólise, sacarificação e tratamento do caldo" representaram $71,7 \%$ do dispêndio energético total. Na cana-de-açúcar, observou-se um custo energético de 2,0MJ $L^{-1}$ em relação ao etanol produzido nas principais operações agronômicas de produção e $19,4 M J L^{-1}$ nas etapas de processamento industrial. A eficiência energética no cultivo e na industrialização foi de 1,1.

Palavras-chave: Saccharum spp., sustentabilidade ambiental, energia renovável, produção agrícola, processamento industrial.

\section{ABSTRACT}

This research analyzed the energetic consumption of the etanol, using as raw-material sugar cane. The searches were carried out from the field in the Midle Paranapanema River Region, Sao Paulo state, in the period from January to December 2007. The referring energy consumption from the crop production phase and industrial processing were evaluated. It was verified that the total energetic cost of the crop production corresponded to $14370.9 \mathrm{MJ} \mathrm{ha}^{-1}$, and the most onerous item was the "inputs" (50.4\%). In the industrial step, the energetic consumption was equivalent to $1,641.56 \mathrm{MJ} \mathrm{t}^{-1}$. The 'hydrolysis, saccharification and broth treatment operations' represented $71.72 \%$ of the total energetic expenditure. It was also observed an energetic cost of $2.0 \mathrm{MJ} \mathrm{L}^{-1}$ in relation to the etanol produced in the main crop production operations, and $19.4 \mathrm{MJ} \mathrm{L}^{-1}$ in the industrial processing. The energy efficiency observed in the crop production and industrialization were of 1.1 .

Key words: Saccharum spp., environmental sustainability, renewable energy, agricultural production, industrial processing.

\section{INTRODUÇÃO}

O Brasil é o maior produtor de cana-deaçúcar do mundo, seguido pela Índia, China e Tailândia, e responde por cerca de $45,0 \%$ da produção mundial de etanol. A cultura da cana-de-açúcar produziu 21,2 bilhões de litros de etanol em 2007/08, dos quais mais de 2,0 bilhões foram destinados à exportação. A área cultivada abrange 6,9 milhões de hectares, correspondendo a 1,9\% da área agriculturável e 18,7\% da área utilizada para culturas anuais (IBGE, 2007). A produção e o processamento de cana-de-açúcar no Brasil são gerenciados pelo setor privado, que obtém os menores custos de produção do mundo, tanto de açúcar, como de álcool, despontando como um segmento altamente competitivo no mercado internacional (GONÇALVES, 2005).

Com a tendência de restrição do uso de hidrocarbonetos fósseis, determinada por pressões

ISecretaria de Extensão Agro-Florestal e Produção Familiar (SEAPROF), 69908-620, Rio Branco, AC, Brasil.

IIAgência Paulista de Tecnologia dos Agronegócios (APTA), 19800-970, Assis, SP, Brasil. E-mail: fernandafurlaneto@apta.sp.gov.br.

*Autor para correspondência.

"IICentro de Raízes e Amidos Tropicais (CERAT), Universidade Estadual Paulista “Júlio de Mesquista Filho” (UNESP), Botucatu, SP, Brasil. 
ambientalistas, econômicas e sociais geradas pelo agravamento do aquecimento global causado pelo efeito estufa, a área cultivada com a cana-de-açúcar deve crescer no país, aproximadamente, 83,0\% nos próximos 10 anos (ANUÁRIO DA AGRICULTURA BRASILEIRA, 2008). No entanto, para que a produção de biocombustíveis seja sustentável ao longo dos anos, são necessários estudos que avaliem o balanço energético da cadeia produtiva como um todo (SALLA, 2008).

Ressalta-se que estudos energéticos diferenciam-se das análises econômicas, pois permitem estimar a energia diretamente consumida e/ou indiretamente utilizada em um processo produtivo. Portanto, possibilitam determinar a dependência ou não de fontes de energia não renováveis, que podem constituir-se como fatores limitantes no processo de produção agrícola.

Nesse sentido, este trabalho objetivou analisar as energias consumidas nas operações de produção agronômica e processamento industrial da cana-de-açúcar, bem como as energias obtidas na forma de etanol na região do Médio Paranapanema, Estado de São Paulo, contabilizando os custos energéticos de todas as operações de processamento, independentemente da natureza ou da fonte de energia utilizada pela agroindústria.

\section{MATERIAL E MÉTODOS}

Fonte de dados

No cultivo, na colheita e no transporte, foram detalhados o número de horas utilizadas com a mão-de-obra e a quantidade de insumos gastos durante as fases de produção. Por fim, realizou-se a conversão das unidades físicas em unidades energéticas. A unidade adotada para o estudo da eficiência energética foi o Joule e seus múltiplos.

Etapa de produção agronômica da cana-de-açúcar

As matrizes dos coeficientes técnicos das operações agronômicas de cultivo, colheita e transporte da cana-de-açúcar foram levantadas no Pólo Regional de Desenvolvimento Tecnológico do Médio Paranapanema, da Agência Paulista de Tecnologia dos Agronegócios (APTA), e no Departamento Agrícola da Associação Rural dos Fornecedores e Plantadores de Cana da Média Sorocabana (ASSOCANA), localizados no Município de Assis, São Paulo, (SP).

Os dispêndios energéticos do processo operacional de cultivo da cana-de-açúcar relacionados à fase de implantação da lavoura foram divididos em partes iguais para os cinco anos de produção, por ser uma atividade única durante toda a vida útil da cultura. Calculou-se o consumo energético com a colheita e manutenção das soqueiras, considerando a produtividade média regional, ou seja, $85 \mathrm{tha}^{-1}$.

As operações de implantação da lavoura corresponderam a duas gradagens aradoras, duas gradagens niveladoras, marcação de carreadores, levantamento dos terraços, aplicação de calcário, sulcação e adubação, carregamento e transporte da muda para o plantio, cobrição, aplicação de herbicida e inseticida.

Consideraram-se, na fase de manutenção das soqueiras, as seguintes operações: subsolagem, adubação, conservação de carreadores, conservação de estradas, aplicação de herbicida, aplicação aérea de maturador, transporte interno dos insumos, manutenção e transporte dos maquinários, colheita mecanizada, transbordo, enleiramento da palha e transporte da cana-de-açúcar para a usina.

O consumo energético do trabalho humano nas operações de implantação e condução do cultivo da cana-de-açúcar foi representado pelas atividades de corte e pelo preparo das mudas; descarregamento, esparramamento e repicagem para o plantio; acabamento e recobrimento do material de propagação; aplicação de herbicida, inseticida e maturador; operações da colheitadeira, transbordo e caminhão de transporte externo; capina manual, enleiramento da palha, subsolagem e adubação; conservação dos carreadores; manutenção de estradas; transporte interno dos insumos; manutenção e transporte de máquinas.

Etapa de processamento industrial da cana-de-açúcar

Os dados relativos ao consumo energético das operações industriais dispendido durante o processamento da cana-de-açúcar foram coletados na Usina Pau D’Alho, no Município de Ibirarema-SP, e na Usina Nova América, em Tarumã-SP, no período de janeiro a dezembro de 2007. Considerou-se, nos valores obtidos, a capacidade máxima de processamento das destilarias, que é de 300t $\mathrm{h}^{-1}$ de cana-de-açúcar para a indústria Pau D’Alho e 500t h ${ }^{-1}$ para a Nova América.

Os pontos de coleta das informações durante o processamento da cana-de-açúcar foram: balanças de pesagem (2); sondas verticais (2); hilos (2); esteiras metálicas (2); mesas alimentadoras (3); picador de cana; tambor alimentador; desfibrador da cana picada; espalhador de cana desfibrada; eletroímã; esteiras de arraste de uma moenda para outra; moendas, sendo quatro ternos com 16 rolos na usina Pau D’Alho e seis ternos com 24 rolos na usina Nova América; peneira rotativa do filtro do caldo; tratamento do caldo 
referente ao aquecimento, resfriamento e decantação; processo de fermentação; destilação do vinho e sistemas de bombeamento necessários à lavagem da cana-de-açúcar, condução do caldo até as dornas e condução do vinho para a coluna de destilação.

Para as análises do consumo energético industrial, adotou-se o termo “desintegração e moagem” para as etapas de pesagem, sondas verticais, hilos, esteiras metálicas, mesas alimentadoras, sistemas de bombeamento de água para lavagem, picador, tambor alimentador, desfibrador, espalhador da cana-de-açúcar desfibrada, esteira de transporte da cana-de-açúcar desfibrada, eletroimã, esteira de arraste de uma moenda para outra, moendas e sistema de bombeamento de água para o último conjunto de moendas.

O termo "hidrólise, sacarificação e tratamento do caldo” foi designado para as operações de tratamento do caldo e bombeamento do mesmo até as dornas. Na etapa da "fermentação", além do processo em si, computou-se o consumo de energia dos agitadores e da bomba de transferência do vinho para as dornas.

$\mathrm{Na}$ etapa da “destilação”, foram considerados a transferência e os agitadores do vinho volante, a transferência do vinho para a coluna de destilação, a bomba de acionamento do flegma, a bomba da vinhaça e a bomba do álcool fino, o agitador e o carregamento do vinhoto, o exaustor de caldeira, as bombas d'água da caldeira e a esteira para o transporte de bagaço.

\section{Índices energéticos}

Os gastos energéticos com as operações mecanizadas foram calculados a partir do consumo de óleo diesel e de etanol, cujos coeficientes energéticos médios equivalem a $40,6 \mathrm{MJ} \mathrm{L}^{-1}$ e $23,37 \mathrm{MJ} \mathrm{L}^{-1}$, respectivamente. (PIMENTEL, 2003). Para a mão-deobra dessas operações, adotou-se o índice de $1,2 \mathrm{MJ} \mathrm{h}^{-1}$, sendo a jornada de trabalho de oito horas (COMITRE, 1993). Para o material de propagação da cana-de-açúcar, utilizou-se o valor de $480,0 \mathrm{MJ} \mathrm{ha}^{-1}$, conforme URQUIAGA et al. (2005), que corresponde a 30,0 $\mathrm{MJ} \mathrm{t}^{-1}$.

Os conteúdos energéticos do calcário, dos herbicidas e dos inseticidas correspondem a $0,2 \mathrm{MJ} \mathrm{kg}^{-1}$, $302,0 \mathrm{MJ} \mathrm{kg}^{-1}, 306,6 \mathrm{MJ} \mathrm{kg}^{-1}$, respectivamente (BUENO, 2002). Na conversão das unidades físicas de nitrogênio total, fósforo e potássio em equivalentes energéticos, utilizaram-se os índices de $73,3 \mathrm{MJ} \mathrm{kg}{ }^{-1}$ para o $\mathrm{N}$ (CAMPOS, 2001); 13,9MJ kg-1 para o $\mathrm{P}_{2} \mathrm{O}_{5}$ (MERCIER, 1978) e 9,2 $\mathrm{MJ} \mathrm{kg}^{-1}$ para o $\mathrm{K}_{2} \mathrm{O}$ (SHAPOURI et al., 2002). Para a adubação de cobertura da cana-de-açúcar, determinaram-se o valor de 73,3MJ kg-1 para o nitrogênio e o valor de $9,2 \mathrm{MJ} \mathrm{kg}^{-1}$ para o $\mathrm{K}_{2} \mathrm{O}$. Para o cálculo do transporte da cana-de-açúcar até a indústria, adotouse uma distância média de $30 \mathrm{~km}$.

O dispêndio energético nas etapas industriais foi relativo ao consumo dos motores elétricos e do vapor fornecido pelas caldeiras. Os valores encontrados, proporcionais ao processamento de uma tonelada de cana-de-açúcar e a obtenção de 84,7 litros de etanol, foram convertidos em megajoule. Procedeu-se à conversão do consumo dos motores elétricos de cavalo-vapor para HP, e um cavalo-vapor (cv) equivale a 1,014HP e $1 \mathrm{HP}$ é igual a 2,684MJ. Na destilação, adotaram-se dois quilos de vapor para cada litro de etanol destilado. No tratamento do caldo, foram utilizados $500 \mathrm{~kg}$ de vapor para cada tonelada de canade-açúcar processada, em que $500 \mathrm{~kg}$ de vapor equivalem a 1.172,3MJ.

O valor da depreciação energética seguiu o índice disponível na literatura para o agroecossistema milho, que corresponde a 250,5MJ ha-1 (BUENO, 2002). Porém, devido à intensidade das operações ser diferente para cada cultivo, esse valor foi ajustado em função do consumo de combustível utilizado nas operações de cultivo da cana-de-açúcar por unidade de área. Assim, proporcionalmente, a depreciação energética adotada neste trabalho foi de 528,6 $\mathrm{MJ} \mathrm{ha}^{-1}$.

\section{RESULTADOS E DISCUSSÃO}

O custo energético para a produção de um hectare de cana-de-açúcar correspondeu a 14.370,9MJ $\mathrm{ha}^{-1}$. Os gastos energéticos mais representativos foram, respectivamente, com os insumos (50,4\%), a condução da lavoura (13,4\%) e a colheita (13,2\%), os quais juntos somaram $76,9 \%$ do consumo energético total. O dispêndio energético de $722,3 \mathrm{MJ} \mathrm{ha}^{-1}$ referente às atividades de preparo de área representou apenas 5,0\% do consumo energético total devido às características da atividade demandarem apenas um preparo de área para os cinco anos de colheitas consecutivas (Tabela 1).

O nitrogênio é um dos elementos mais exigidos na cultura da cana-de-açúcar (ORLANDO FILHO et al., 1980). Esse nutriente, por ser de alto conteúdo energético, eleva consideravelmente o consumo de energia na etapa produtiva e pode tornar a cultura energeticamente insustentável ao longo dos anos. A adoção de medidas que otimizem as fontes energéticas de origem biológica, como a utilização de adubos orgânicos e o uso de combustíveis renováveis, pode reduzir o dispêndio energético da cultura. Já, no item "condução da lavoura”, o controle de plantas invasoras pode chegar a representar de 35,0 a 45,0\% do custo da implantação e condução de um canavial (LORENZI, 1986). 
Tabela 1 - Demonstrativo do custo energético para a produção de cana-de-açúcar, em $\mathrm{MJ} \mathrm{ha}^{-1} \mathrm{e} \%$, na região paulista do Médio Paranapanema, 2007.

\begin{tabular}{lll}
\hline Operações de cultivo da cana-de-açúcar & MJ ha $^{-1}$ & $\%$ \\
\hline Preparo da área & 722,3 & 5,0 \\
Plantio & 329,1 & 2,3 \\
Insumos & $7.239,0$ & 50,4 \\
Condução da lavoura & $1.922,4$ & 13,4 \\
Colheita & $1.900,8$ & 13,2 \\
Transporte até a indústria & $1.729,6$ & 12,0 \\
Depreciação energética & 527,7 & 3,7 \\
Total & $14.370,9$ & 100,0 \\
\hline
\end{tabular}

Fonte: Dados de pesquisa, 2007.

O consumo energético industrial total para o processamento da cana-de-açúcar correspondeu a $1.641,6 \mathrm{MJ} \mathrm{t}^{-1}$ e $139.532,2 \mathrm{MJ} \mathrm{ha}^{-1}$. As operações de "hidrólise, sacarificação e tratamento do caldo" representaram 71,7\%. A “destilação” representa 24,3\% do dispêndio energético total em decorrência do alto consumo de vapor que é utilizado no aquecimento do mosto visando a principalmente dois objetivos: esterilizar o meio para diminuir a contaminação da fermentação e adicionar enzimas para hidrolisar algumas cadeias de amido existentes no caldo da cana (Tabela 2).

SOUZA (2006) destaca que a indústria sucroalcooleira vem investindo na área agrícola e industrial com o objetivo de elevar a produção por meio do aumento da produtividade, da expansão das unidades produtivas e das inovações tecnológicas. Uma dessas tecnologias que vem sendo desenvolvida, inclusive pelo Brasil, é a produção de álcool a partir da celulose por meio do processo de hidrólise, visto que as matérias-primas celulósicas são menos onerosas do que, por exemplo, o milho. No entanto, o custo para converter a celulose em etanol é muito elevado. Desse modo, o grande desafio científico é reduzir o custo desse processo e tornar essa tecnologia viável economicamente e ambientalmente (MACEDO, 2005).

A cana-de-açúcar apresentou um custo energético de 2,0 $\mathrm{MJ} \mathrm{L}^{-1}$ em relação ao etanol produzido nas principais operações agronômicas de produção de cana-de-açúcar e $19,4 \mathrm{MJ} \mathrm{L}^{-1}$ nas etapas de processamento industrial (Tabela 3). Os resultados desta pesquisa são semelhantes aos dados encontrados por URQUIAGA et al. (2005), os quais verificaram que os itens que demandaram mais consumo energético correspondem aos "insumos”, “colheita” e "preparo da área”.

Os custos energéticos totais, considerando o consumo nas etapas de produção e de processamento, somaram $21,8 \mathrm{MJ} \mathrm{L}^{-1}$. Sabendo que a energia de um litro de etanol corresponde a 23,7MJ, tem-se que a eficiência energética da cana-de-açúcar equivale a 1,1 .

\section{CONCLUSÕES}

A cadeia da cana-de-açúcar é potencialmente sustentável e pode contribuir como uma alternativa energética para vários segmentos que demandam combustíveis, sendo necessárias pesquisas na área fitotécnica e industrial que possam desonerar energeticamente as respectivas operações.

Há necessidade de outros estudos para validação dos parâmetros utilizados e que também contemplem o uso do bagaço da cana-de-açúcar na cogeração de energia e emissão de $\mathrm{CO}_{2}$ na atmosfera, bem como a comparação com outras matérias-primas para produção de etanol, tais como o milho e a mandioca, como forma de contribuição e aumento da massa crítica pertinente ao assunto, visto que são poucos os trabalhos que tratam do assunto de forma quantificável.

Tabela 2 - Demonstrativo do custo energético para o processamento da cana-de-açúcar, em MJ ha ${ }^{-1}$ e \%, na região paulista do Médio Paranapanema, 2007.

\begin{tabular}{llll}
\hline Etapa industrial da cana-de-açúcar & MJ t$^{-1}$ & MJ ha $^{-1}$ & \% \\
\hline Desintegração e moagem & 61,9 & $5.258,7$ & 3,8 \\
Hidrólise, sacarificação e tratamento caldo & $1.179,5$ & $100.260,5$ & 71,7 \\
Fermentação & 0,4 & 31,9 & 0,1 \\
Destilação & 399,3 & $33.939,0$ & 24,3 \\
Manutenção & 0,5 & 42,1 & 0,1 \\
Consumo industrial total & $1.641,6$ & $139.532,2$ & 100,0 \\
\hline
\end{tabular}

Fonte: Dados de pesquisa, 2007. 
Tabela 3 - Demonstrativo do custo energético para produzir um litro de etanol nas principais operações de produção e processamento da cana-de-açúcar, em $\mathrm{MJ} \mathrm{L}^{-1}$, na região paulista do Médio Paranapanema, 2007.

\begin{tabular}{lcl}
\hline Operações de produção da cana-de-açúcar & MJ L & \% \\
\hline Preparo de área & 0,1 & 5,0 \\
Plantio & 0,1 & 2,5 \\
Insumos & 0,9 & 50,3 \\
Condução da lavoura & 0,3 & 13,5 \\
Colheita & 0,3 & 13,1 \\
Transporte a Indústria & 0,2 & 12,1 \\
Depreciação energética & 0,1 & 3,5 \\
Total & 2,0 & 100,0 \\
& & \\
Operações de processamento da cana-de-açúcar & MJ L ${ }^{-1}$ & $\%$ \\
Desintegração /moagem & 0,7 & 1,9 \\
Hidrólise /sacarificação /Tratamento do caldo & 13,8 & 56,1 \\
Fermentação & 0,1 & 0,5 \\
Destilação & 4,7 & 41,2 \\
Manutenção & 0,1 & 0,3 \\
Total & 19,4 & 100,0 \\
\hline
\end{tabular}

Fonte: Dados de pesquisa, 2007.

\section{REFERÊNCIAS}

ANUÁRIO DA AGRICULTURA BRASILEIRA. Mercado e perspectivas - cana. São Paulo: Instituto FNP, 2008. 497p.

BUENO, O.C. Eficiência cultural do milho em assentamento rural, Itaberá/SP. 2002. 147f. Tese (Doutorado em Energia na Agricultura) - Faculdade de Ciências Agronômicas, Universidade Estadual Paulista de Botucatu, Botucatu, SP. Disponível em: <http:/ /www.athena.biblioteca.unesp.br/exlibris/bd/bla/ 33004064021P7/2002/bueno_oc_dr_botfca.pdf>. Acesso em: 10 mar. 2008.

CAMPOS A.T. Balanço energético relativo à produção de feno de “coast-cross” e alfafa em sistema intensivo de produção de leite. 2001. 236f. Tese (Doutorado em Energia na Agricultura) - Faculdade de Ciências Agronômicas, Universidade Estadual Paulista de Botucatu, Botucatu, SP. Disponível em: <http://www.athena.biblioteca.unesp.br/ exlibris/ bd/bla/33004064021P7/2001/campos_at_dr_botfca.pdf $>$. Acesso em: 18 abr. 2008.

COMITRE, V. Avaliação energética e aspectos econômicos da filière soja na região de Ribeirão Preto. 1993. $152 \mathrm{f}$. Dissertação (Mestrado em Planejamento Agropecuário) Faculdade de Engenharia Agrícola, Universidade Estadual de Campinas, Campinas, SP. Disponível em: <http:// libdigi.unicamp.br/document/?code=vtls000081652>. Acesso em: 06 jun. 2008.

GONÇALVES, D.B. Dilemas do desenvolvimento sustentável na produção canavieira paulista. 2005. 96f. Tese (Doutorado em Engenharia de Produção) - Faculdade de Engenharia de Produção, Universidade Federal de São Carlos, São Carlos, SP. Disponível em: <http://200.136.241.56/htdocs/tedeSimplificado/ tde_busca/processaPesquisa.php?pesqExecutada=1\&id=833>. Acesso em: 28 jul. 2008.

IBGE. Pesquisa industrial produção física: agroindústria. Rio de Janeiro, 2007. Disponível em: <http://www.sidra.ibge.gov.br/ bda/agric/default.asp?z=t\&o=11\&i=P>. Acesso em: 20 jun. 2008.

LORENZI, H. Plantas invasoras: uma séria ameaça aos canaviais. São Paulo: COPERSUCAR, 1986. 102p. (Boletim Técnico, 35).

MACEDO, I.C. A energia da cana-de-açúcar: doze estudos sobre a agroindústria da cana-de-açúcar no Brasil e a sua sustentabilidade. São Paulo: ÚNICA, 2005. 273p. Cap.11, p.185-193.

MERCIER, J.R. Energie et agriculture, le choix ecologique. Paris: Debard, 1978. 187p.

ORLANDO FILHO, J. et al. Crescimento e absorção de macronutrientes pela cana-de-açúcar, variedade CB 4176, em função da idade, em três solos do Estado de São Paulo. Piracicaba: PLANALSUCAR, 1980. 127p. (Boletim Técnico, 1).

PIMENTEL, D. Ethanol fuels: Energy balance, economics, and environmental impacts are negative. Natural Resources Research, Califórnia, v.12, n.2, p.127-134, 2003. Disponível em: <http://www.ethanol-gec.org/netenergy/neypimentel.pdf>. Acesso em: 14 jun. 2008.

SALLA, D.A. Análise energética de sistemas de produção de etanol de mandioca, cana-de-açúcar e milho. 2008. 168f. Tese (Doutorado em Energia na Agricultura) - Faculdade de Ciência Agronômicas, Universidade Estadual Paulista de Botucatu, Botucatu, SP. Disponível em: <http://www.fca.unesp.br/ pos_graduacao/teses/PDFs/Arq0279.pdf $>$. Acesso em: 10 jun. 2008.

SHAPOURI, H. et al. The energy balance of corn ethanol: an update. Washington: US Department of Agriculture, 2002. 19p. Disponível em: <http://www.usda.gov/oce/reports/ energy/ aer-814.pdf $>$. Acesso em: 20 jul. 2008.

SOUZA, R.R. Panorama, oportunidades e desafios para o mercado mundial de álcool automotivo. 2006. $129 \mathrm{f}$. Dissertação (Mestrado em Ciência em Planejamento Energétcio) - Faculdade de Engenharia, Universidade Federal do Rio de Janeiro, Rio de Janeiro, RJ. Disponível em: <http:// www.ppe.ufrj.br/ppe/production/tesis/raquelrs.pdf $>$. Acesso em: 25 jul. 2008.

URQUIAGA, A. et al. Produção de biocombustíveis: a questão do balanço energético. Política Agrícola, Brasília, v.14, n.1, p.42-46, 2005. Disponível em: <http://www.agronegociose.com.br/agr/down/artigos/Pol_Agr_1_2005_Art06.pdf $>$. Acesso em: 15 jun. 2008. 